Oikos 119: 45-52, 2010

doi: $10.1111 / \mathrm{j} .1600-0706.2009 .17591 . x$,

(C) 2009 The Authors. Journal compilation (C) 2009 Oikos Subject Editor: Franz Weissing. Accepted 15 June 2009

\title{
Can the failure to punish promote cheating in mutualism?
}

\author{
David P. Edwards, Felicity A. Ansell, Paul Woodcock, Tom M. Fayle, \\ Chey V. K. and Keith C. Hamer
}

D. P. Edwards (d.p.edwards@leeds.ac.uk),F. A. Ansell, P. Woodcock and K. C. Hamer, Inst. of Integrative and Comparative Biology, Univ. of Leeds, Leeds, LS2 9JT, UK. - T. M. Fayle, Insect Ecology Group, Univ. Museum of Zoology Cambridge, Downing Street, Cambridge CB2 3EJ, UK. - Chey V. K., Forest Research Centre, Sandakan, Sabah, Malaysia.

\begin{abstract}
A key challenge in the study of mutualism is to understand the mechanisms that prevent cheating. In some systems, host retaliation against cheaters prevents the breakdown of cooperation. Here, we focus on the converse of this demonstration, and ask whether hosts that fail to retaliate are commonly inhabited by cheaters. We do so using the classic ant-plant interaction, in which plants provide ant-housing (domatia) in return for protection from herbivores. Our model system is the rattan ant-palm Korthalsia furtadoana, which grows swollen leaf sheaths as domatia and associates with two species of obligate host-ants, Camponotus sp90 and C. sp93, and with facultative Crematogaster and 'tramp' ant species. One ant-tree species is known to retaliate by tying the growth of domatia to the successful protection of new leaves, and non-protecting cheaters are rare. In contrast, $K$. furtadoana grows the domatium before the new leaf develops, suggesting that sanctioning may not be possible. We experimentally simulated herbivory by cutting leaves from shoots and found no difference in the mortality and growth of domatia on such 'cheated' shoots than on controls, confirming that $K$. furtadoana cannot sanction non-protectors. We then investigated the intensity of protection that Camponotus and Crematogaster antsymbionts provide K. furtadoana. We demonstrate that C. sp90, which only inhabit half of colonised plants, vigorously protects leaves, that C. sp93 rarely protects, and that Crematogaster never protects. We then show that plants inhabited by C. $s p 90$ have a higher growth rate than those inhabited by C. sp93. We conclude that $C . s p 90$ is a protection mutualist, while C. sp93 and Crematogaster are parasites, the first such demonstrations for an ant-palm interaction. The presence of commonly occurring parasites, as well as rare tramp ants, provides the first clear correlative evidence that an inability to punish results in abundant cheating.
\end{abstract}

A key challenge in the study of inter-specific cooperation, or mutualisms, is to understand the mechanisms that prevent cheating. Several overlapping theories, with different degrees of generality, have been developed to explain the maintenance of cooperation in the face of (a) invasion by parasites that purloin the benefits one mutualist provides another, and (b) selection for cheating behaviour among the mutualists themselves (Doebeli and Knowlton 1998, Yu 2001, Sachs et al. 2004, Foster and Wenseleers 2006).

One concept that is proving promising is partner choice. Partner choice mechanisms rely on asymmetries in symbiotic relationships (unequal 'power,' Bergström et al. 2003, Frank 2003) in which the partner holding the physical resource (the host) 'coerces' the partner providing the services (the visitor) into acting cooperatively by selectively directing benefits to cooperator genotypes and/or selectively terminating interactions with cheaters (Bull and Rice 1991, Pellmyr and Huth 1994, West and Herre 1994, Yu 2001, Ferdy et al. 2002, West et al. 2002a, 2002b, Hoeksema and Kummel 2003, Kiers et al. 2003, Shapiro and Addicott 2003, Holland et al. 2004, Edwards et al. 2006, Foster and Wenseleers 2006, Kiers and van der Heijden 2006, Edwards and Yu 2007, Johnstone and Bshary 2008).
A simple manifestation of partner choice is the thost sanction', in which cheating visitors are punished by their hosts. For example, in the yucca-moth mutualism, yucca flowers heavily damaged by the oviposition of some species of pollinating yucca moth tend to be aborted (Pellmyr and Huth 1994), which selects for lower levels of oviposition, and thus higher seed set. Similarly, in the legume-rhizobia mutualism, soybean plants selectively reduce oxygen permeability in root nodules containing non-nitrogen fixing rhizobial bacteria (Kiers et al. 2003), decreasing their fitness (West et al. 2002b; see also Hoeksema and Kummel 2003 on mycorrhizae).

The host sanctions concept suggests that by imposing costs on cheaters and directing benefits to mutualists, the host is able to promote the evolution and maintenance of cooperation. This prediction is supported by several studies that provide evidence of abundant cooperation in the presence of host sanctions (Pellmyr and Huth 1994, Kiers et al. 2003, Edwards et al. 2006). However, the host sanctions concept also makes the prediction that systems that lack retaliation will be dominated by non-cooperators, promoting the evolution of parasitism. Rigorous examination of the host sanctions concept therefore requires both 
empirical and experimental evidence from systems that lack retaliation, to test this prediction. To our knowledge, however, no previous study has addressed this issue.

Here, we focus on another classic mutualistic interaction, that between ants and plants (Janzen 1966). In these interactions, ant-plants (also called myrmecophytes) provide resident ant colonies with housing in the form of domatia, and sometimes food, in return for protection from herbivores (Davidson and McKey 1993, Heil and McKey 2003, Rico-Gray and Oliveira 2007). Previous experimental work has demonstrated that the Cordia nodosa ant-tree responds to new leaf damage by reducing the growth and survival of the attached ant housing, thus imposing a host sanction (Edwards et al. 2006). Edwards et al. proposed that the adaptation that enables sanctioning in ant-plants is not the death of the new shoot upon leaf damage, which is a preadapted trait present in many non-myrmecophytic plants, but is the location of the domatium with each new shoot and leaf package. The presence of a host sanction in this system is associated with over $95 \%$ of plants being inhabited by protecting ant-symbionts (Yu et al. 2001, 2004, Edwards et al. 2006), providing correlative evidence that sanctioning promotes protection of $C$. nodosa by its host-ants.

\section{Study system}

Our study system is the rarely studied form of myrmecophytism, that between ants and Bornean rattan palms (Mattes et al. 1998), in which host-palms provide resident ant colonies with domatia, and in return plants may receive protection from herbivores. Korthalsia is the only ocreabearing rattan in Borneo that produces greatly swollen ocrea and that interacts with ants (Dransfield and Patel 2005), strongly suggesting that Korthalsia has evolved swollen ocrea as domatia (ant-housing). We thus use the myrmecophytic palm Korthalsia furtadoana as our model system, which is a very abundant ( 75 plants ha ${ }^{-1}$ in this study), climbing and clustering species (Dransfield 1984). Housing is apparently the only incentive offered to host-ants by $K$. furtadoana, with no food bodies or extra-floral nectaries identified despite extensive searching with a microscope (Edwards and Woodcock unpubl.). As in other ant-plants, $K$. furtadoana develops new domatia at the site of new shoot growth (Edwards et al. 2006). However, in contrast to the antCordia nodosa tree system, which develops house and leaf at the same time, $K$. furtadoana develops the new domatium before the new leaf beings to grow (Fig. 1). Additionally, ants must chew entry holes in new domatia, which develop without entrances (Fig. 1a), making housing open-access to potential ant colonists.

Korthalsia furtadoana is commonly colonised by two species of Camponotus (Formicinae) ants, with one colony of either species per plant. These species are known from voucher specimens and have the provisional names C. sp90 Yamane (subgenus Myrmoplatys) and C. sp93 Yamane (subgenus unknown). Both these species appear to be obligate symbionts of $K$. furtadoana since despite extensive sampling, neither has been collected from other ant-plants or recorded in leaf litter (N. Tawatao and Woodcock unpubl.), and they house the colony queen, larvae, and reproductive alates within the domatia (Edwards and Fayle unpubl.).

A number of rarer ant species also associate with Korthalsia furtadoana. The most prevalent of these is Crematogaster spp. (Myrmicinae), which colonise and inhabit domatia, and are active at the entrance holes of the domatia and more rarely along the plant stems. Other ants that were encountered were: Technomyrmex spp. and Tapinoma sp. (Dolichoderinae); Paratrechina spp. and Plagiolepis sp. (Formicinae); and Pheidole spp., Vombisidris spp., Monomorium sp., Strumigenys sp., and Tetramorium sp. (Myrmicinae). Each of these other 'tramp' ant species again colonise and inhabit domatia, but they do not appear to forage on or protect the plant, and their presence could only be confirmed when domatia were dissected. Crematogaster and many of the tramp ant species house the queen, alates, and larvae within the domatia, and colony investment appears to be directed almost entirely to reproduction,
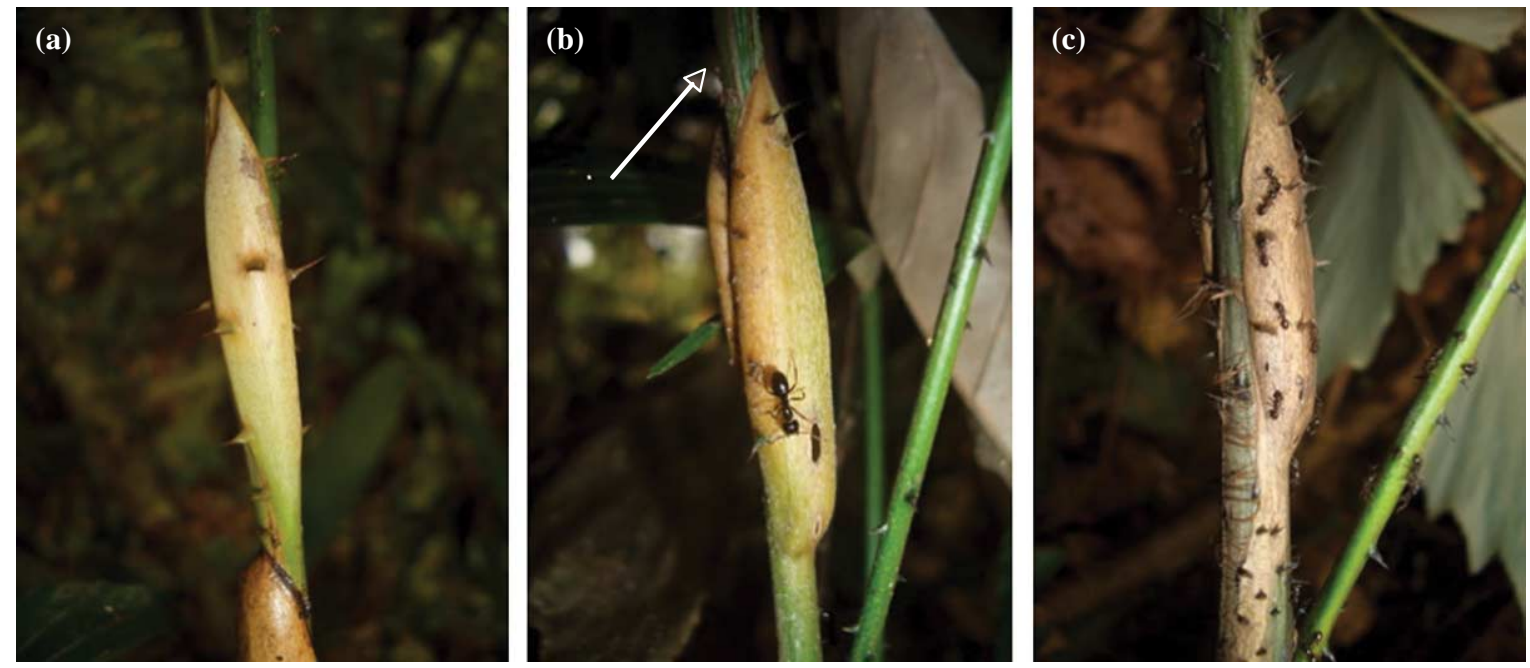

Figure 1. Korthalsia furtodoana. (a) the domatium develops before the new leaf. (b) the new leaf then grows from the top of the domatium (see arrow). The domatium is protected by a Camponotus sp93. (c) mature rattan domatium and stem vigorously protected by C. $s p 90$. 
with colonies reproducing at very small sizes $(\approx 2$ domatia; Edwards and Fayle unpubl.). Most likely, however, none of these ant species is an obligate symbiont since many have been collected in the leaf-litter or in bird's nest ferns, and they thus form facultative, opportunistic interactions with K. furtadoana.

The observation that Korthalsia furtadoana produces the domatium before the new leaf develops (Fig. 1a-b) suggests that it is unable to tie the successful development of new leaves to the provision of housing. We therefore test two hypotheses in this paper:

1. Korthalsia furtodoana does not impose a host sanction to punish non-protecting cheaters.

2. A lack of retaliation is associated with a high incidence of non-protection by ant-symbionts.

\section{Material and methods}

All work was carried out in lowland dipterocarp forest in the Ulu Segama Forest Reserve, Sabah, Malaysia $\left(4^{\circ} 58^{\prime} \mathrm{N}\right.$, $\left.117^{\circ} 48^{\prime} \mathrm{E}\right)$. The study was conducted between July 2007 and July 2008 in the environs of the Danum Valley Research Centre. The study area had been selectively logged between 1988-1989, in which commercial stems $>0.6 \mathrm{~m}$ diameter were removed resulting in ca $80 \mathrm{~m}^{3}$ of timber extracted ha ${ }^{-1}$ (Whitmore 1984). There are two seasons in northeast Borneo, with a relatively dry period of the year between April and September (Walsh and Newberry 1999), in which the majority of the fieldwork was conducted.

\section{Do ant-palms impose a host sanction?}

\section{Benefit of inhabiting a large plant}

To determine whether ants benefit from inhabiting a larger plant, and therefore if a host sanction can operate in this system, we investigated the effect of plant size on ant reproduction. All domatia on sampled plants inhabited by Camponotus $s p 90$ or by C. sp93 were collected and placed in alcohol. The number of winged-male and of winged-female alates within each domatium and the number of domatia opened (plant size) were recorded. Twenty-seven replicates were conducted for C. sp90 and seventeen for C. sp93.

To calculate investment of ant biomass in reproduction, Camponotus sp90 ( $\left.\mathrm{n}_{\text {male }}=7 ; \mathrm{n}_{\text {female }}=9\right)$ and C. sp93 $\left(n_{\text {male }}=9 ; n_{\text {female }}=5\right)$ alates, one of each sex per colony, were oven-dried for $48 \mathrm{~h}$ at $50^{\circ} \mathrm{C}$. Each individual was removed separately from the oven and immediately weighed to prevent absorption of ambient moisture. We corrected for overestimation of the cost of producing reproductive females relative to males using the equation $\mathrm{W}_{\mathrm{f}}^{\text {corrected }}=$ $(\mathrm{Wf} / \mathrm{Wm})^{0.7} \mathrm{Wm}$, where $\mathrm{W}_{\mathrm{f}}$ is the average dry mass of a female and $\mathrm{W}_{\mathrm{m}}$ is the average dry mass of a male (Boomsma 1989).

\section{Host sanction experiment}

To examine the effect of leaf damage on the survival and growth of associated domatia, we experimentally simulated herbivory on naturally established Korthalsia furtadoana plants inhabited by Camponotus, following Edwards et al. (2006). One experiment used new shoots (non-lignified), at the tip of the stem, and the other used mature shoots (lignified). In both experiments, we removed the new or mature leaf, $1 \mathrm{~cm}$ from the base of the petiole, using a scissors. Individual shoots were assigned to treatment or to control by coin flip, and in most cases we used plants producing two shoots, allowing within-plant controls. During the course of the experiment, ants continued to reside in and to protect domatia.

The initial maximum width and length of all domatia were measured to the nearest $1 \mathrm{~mm}$ using callipers. Domatia were scored for mortality after 30 days. Surviving domatia were re-measured and the number of new shoots growing from the focal domatium was recorded. For new shoots, we used 17 plants producing two new shoots and 26 plants producing one new shoot $\left(\mathrm{n}_{\text {treatment }}=13\right)$. For mature shoots, we used 30 plants and, on each plant, we randomly selected two domatia with mature leaves (from the fourth to seventh domatia below the apical shoot, to ensure that leaves had fully lignified) and assigned one to the treatment by coin flip.

To convert linear dimensions to volume, we randomly collected a domatium from each of 23 naturally established palms. The domatium sheath was removed from the main stem, and the volume was measured directly by using a syringe to fill the upturned domatium with water. We also estimated volume using the equation for a third of a cylinder: $\mathrm{V}=\frac{1}{3} \pi \mathrm{r}^{2} \mathrm{~L}$, where $\mathrm{r}$ is the radius of the domatium and $\mathrm{L}$ the length. Observed and calculated volumes were highly correlated (Pearson, $\mathrm{r}=0.87, \mathrm{p}<0.001$ ).

\section{Does a failure to punish enable cheating?}

\section{Patrolling of new and of mature leaves}

To determine the amount of protection provided by Camponotus sp90, C. sp93, and tramp ants we recorded the number of ants patrolling on one new (when present) and one mature leaf per plant. If the palm had more than one new leaf, the test new leaf was randomly chosen by coin flip. The test mature leaf was randomly selected (as above). All surveys were conducted between 08:00 and 13:00. Fiftythree new and 62 mature leaves were surveyed on Camponotus sp90-, 36 new and 41 mature leaves on Camponotus sp93-, and three new and seventeen mature leaves on Crematogaster-inhabited palms.

\section{Defence against model herbivore}

To determine whether ants locate a model herbivore and the intensity of defence, we conducted baiting experiments with termites on Camponotus sp90- and C. sp93-inhabited palms (Heil et al. 2004, Tillberg 2004). Termites represent suitable model herbivores because we were able to use related individuals from the same nest, allowing us to control for inter-specific and individual variation that could bedevil the use of most herbivores.

Location. A mature leaf was randomly selected (see above), and a single termite and a paper control $(1.0 \times$ $0.5 \mathrm{~cm}$ ) sample were pinned to the second pair of leaflets 
counted from the leaf base (one sample on the left- and the other the right-hand leaflet). Each sample was pinned $3 \mathrm{~cm}$ from the petiole along the midline of the leaflet. The time at which each sample was first located by a worker ant was recorded, with a find classed as an ant touching the sample with its antennae or mandibles. If a sample was not located within ten minutes the experiment was terminated.

Defence. Once a sample had been located, the maximum number of ants present on the leaflet was recorded. Also, the time that ants spent recruiting attackers and/or attacking the sample was recorded until ten minutes had elapsed, the sample was consumed or removed from the leaflet, or all ants had left the leaflet and not returned within one minute.

After each experiment, the pins were washed with ethanol to remove any pheromones, and a new termite and paper control were used for each replicate. Sample entry order and leaflet position were randomised. Thirtyseven replicates were conducted for Camponotus $s p 90$ and 32 for C. sp93, with one replicate per plant.

\section{Leaf herbivory}

To quantify the effectiveness of protection provided by the ant-symbionts, we investigated herbivory of mature leaves on plants inhabited by Camponotus sp90 $(\mathrm{n}=67)$, by Camponotus sp93 $(\mathrm{n}=42)$, and by Crematogaster $(\mathrm{n}=10)$, and on uncolonised plants $(n=46)$. A mature leaf on each plant was randomly selected (as above), removed, and photographed against a white background. A leaf consists of a central stem from which several leaflets develop, and each leaflet was scored for the percentage eaten, where: $0=0 \%$; $1=1-20 \% ; 2=21-40 \% ; 3=41-60 \% ; 4=61-80 \%$; and $5=81-100 \%$. Because each leaflet has an obvious join with the central stem, we were confidently able to identify leaflets that had been completely eaten by herbivores, thus avoiding type II errors. Herbivory for the complete leaf was calculated by taking the average of the scores for the leaflets.

\section{Growth of host plants}

To assess the host benefit of protection by ants, we followed the growth of new shoots over a period of nine months on sixteen Camponotus sp90 and on twelve C. sp93. After nine months we recorded the number of domatia that had developed on each focal plant shoot.

\section{Ant abundance}

Korthalsia furtadoana was surveyed by line transect, and each plant encountered was scored for ant inhabitant (Camponotus sp90, Camponotus sp93, Crematogaster, or uncolonised).

\section{Statistical analyses}

Data were analysed using general linear models, $\log 10$ transforming data where necessary to normalise residuals, and removing non-significant interaction terms where appropriate. Because the number of ants patrolling are counts, they were analysed using generalised linear models with Poisson error and a log link. The location of termite and paper baits by ants was scored as a success or failure in each replicate and data were analysed using a generalised linear model with binomial error and a logit link. Analyses were conducted using GLM Stat ver. 5.7.7. and SPSS ver. 14.0 , and in all cases residuals were normally distributed and homoscedastic. Means are presented \pm 1 SE.

\section{Results}

\section{Do ant-palms impose a host sanction?}

\section{Benefit of inhabiting a large plant}

There was a significantly positive effect of plant size (number of domatia) on ant reproductive biomass (GLM: $\mathrm{F}_{1,42}=60.2, \mathrm{p}<0.0001$ ), and Camponotus sp93 produced $\mathrm{a}$ significantly greater reproductive biomass than did C. $s p 90$ $\left(\mathrm{F}_{1,42}=8.7, \mathrm{p}=0.0053\right)$. There was no interaction between species and plant size $(\mathrm{p}>0.75)$.

\section{Host sanction experiment}

Initial volumes of treatment and control domatia did not differ for either the new domatia (mean volume \pm SE: treatment $=1.08 \mathrm{ml} \pm 0.13 ; \quad$ control $=1.17 \mathrm{ml} \pm 0.11)$ or the mature domatia (treatment $=1.80 \mathrm{ml} \pm 0.15$; control $=1.90 \mathrm{ml} \pm 0.15$ ) experiment (both $\mathrm{p}>0.5$ ). There was no effect of experimental removal of new leaves on survival of domatia ( $97 \%$ survival, $\mathrm{n}=30$ ) compared to controls $(100 \%, \mathrm{n}=30)$. Additionally, there was extremely limited additional growth of a given domatia, and what little growth had occurred did not differ between the test domatia (mean growth $=2.51 \mu \mathrm{l} \pm 1.3 \mathrm{SE}$ ) compared to controls $\left(4.88 \mu \mathrm{l} \pm 3.6\right.$; GLM: $\left.\mathrm{F}_{1,57}=0.4, \mathrm{p}=0.54\right)$, confirming that domatia had completed most of their development before the attached new leaf had fully grown and lignified (Fig. 1). Furthermore, there was no difference in the number of new domatia developed on the treatment (mean number of domatia $=0.93 \pm 0.1 \mathrm{SE}$ ) or control $(0.83 \pm 0.1)$ shoots (GLM: $\left.F_{1,57}=0.2, p=0.63\right)$. Similarly, there was no effect of removing mature leaves on survival or growth of attached domatia (both $\mathrm{p}>0.25$ ). These data strongly indicate that $K$. furtadoana is unable to impose a host sanction.

\section{Does a failure to punish enable cheating?}

\section{Patrolling of new and of mature leaves}

Patrolling of new leaves was twenty-fold more intensive by Camponotus sp90 than by C. sp93, and C. sp93 did not patrol mature leaves (Fig. 2). Crematogaster did not patrol leaves at all. Additionally, across all species, new leaves were more intensively patrolled than mature leaves (Fig. 2). This pattern of patrolling provision held across all months that these authors worked on this system, and we never observed patrolling by tramp ants (March-November; Edwards et al. unpubl.).

\section{Defence against model herbivore}

Location

Camponotus sp90 detected termites and paper controls significantly more frequently than did C. sp93 (Fig. 3a). In cases where the sample was detected, there was no effect 


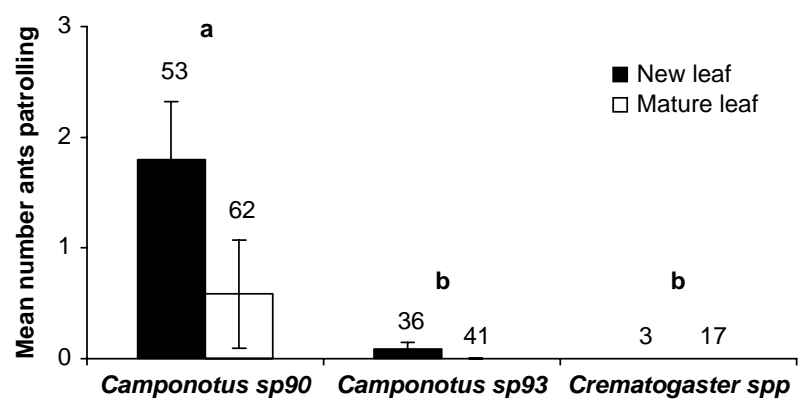

Figure 2. Patrolling of new and of mature leaves. The amount of patrolling differed significantly between species (GLM with Poisson error and a log link: $\mathrm{DF}=1, \chi^{2}=129.3, \mathrm{p}<0.0001$ ). Pairwise comparisons revealed that Camponotus sp90 patrolled significantly more than $C . \operatorname{sp} 93\left(\chi^{2}=111.0, \mathrm{DF}=1, \mathrm{p}<0.0001\right)$ and than Crematogaster $\left(\chi^{2}=42.0, \mathrm{DF}=20, \mathrm{p}=0.003\right)$, and that there was no difference in patrolling between $C$. sp93 and Crematogaster $\left(\chi^{2}=1.4, \mathrm{DF}=20, \mathrm{p}>0.75\right)$. Additionally, across all species, new leaves were patrolled significantly more than mature leaves (GLM, Poisson error and $\log \operatorname{link}$ : DF $=1, \chi^{2}=$ 40.3, $\mathrm{p}<0.0001)$. There was no interaction between species and leaf maturity $(\mathrm{p}>0.75)$. Letters denote significant differences in patrolling between species at the $\mathrm{p}<0.01$ level, sample sizes are given, and bars represent $\pm 1 \mathrm{SE}$.

(a)

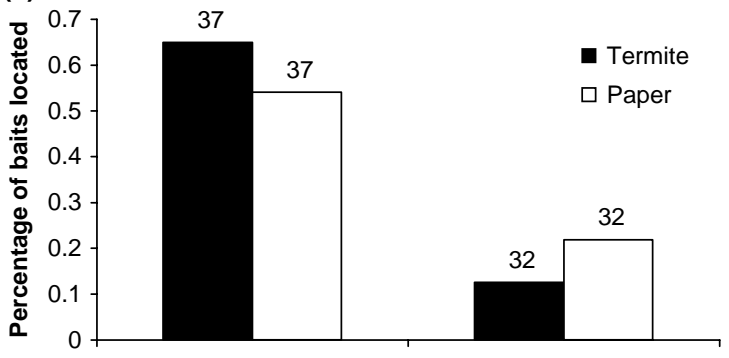

(b)

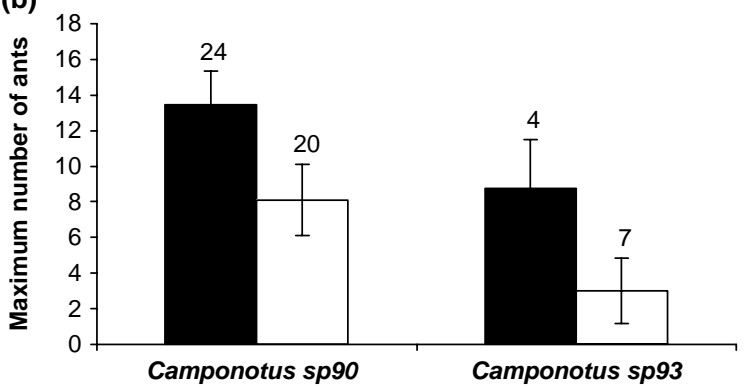

Figure 3. Ant defence against herbivores. (a) Camponotus sp90 located significantly more samples than did C. sp93 (GLM with binomial error and a logit link: $\mathrm{DF}=1, \chi^{2}=26.9, \mathrm{p}<0.0001$ ). There was no difference in the frequency of detection of the model herbivore (termite) compared to the paper control ( $p>0.75)$. (b) Of those colonies that located the model herbivore and/or the control, C. sp90 recruited more workers than did C. sp93 (GLM with Poisson error and a log link: $\left.\mathrm{DF}=1, \chi^{2}=26.3, \mathrm{p}<0.0001\right)$, and more workers visited termite baits than controls $(\mathrm{DF}=1$, $\left.\chi^{2}=41.0, \mathrm{p}<0.0001\right)$. In both cases, there was no interaction between species and sample type (all $\mathrm{p}>0.05)$. Sample sizes are given and bars represent $\pm 1 \mathrm{SE}$. of ant species or sample type on the time taken to locate a sample (both $\mathrm{p}>0.5$ ).

\section{Defence}

Of those colonies that located a sample, a significantly higher maximum number of $C . s p 90$ than of $C . s p 93$ workers recruited, and maximum recruitment was significantly greater to the termite than to the control (Fig. 3b). Additionally, both $C . s p 90$ and $C$. sp93 attacked the model herbivore (mean time \pm SE: C. $s p 90=460 \mathrm{~s} \pm 47$; C. $s p 93=492 \mathrm{~s} \pm 108$ ) for significantly longer than against the paper control (mean time \pm SE: C. $s p 90=312 \mathrm{~s} \pm 57$; C. $s p 93=98 \mathrm{~s} \pm 65) \quad\left(\mathrm{GLM}: \mathrm{F}_{1,53}=10.7, \mathrm{p}=0.0019\right)$. There was no effect of species on the duration of defence $(\mathrm{p}>0.2)$.

\section{Leaf herbivory}

Mature leaves experienced significantly lower herbivory on palms inhabited by Camponotus $s p 90$ than by $C . s p 90$ or by Crematogaster (Fig. 4). However, the presence both of C. $s p 90$ and of C. sp93 reduced herbivory significantly compared to uncolonised saplings, while Crematogaster did not differ in herbivory compared to C. sp93 or to uncolonised plants (Fig. 4).

\section{Growth of host plants}

Palms inhabited by Camponotus sp90 exhibited significantly higher growth after nine months than did those inhabited by C. $s p 93$ (Fig. 5), indicating a cost to Korthalsia furtodoana of hosting C. sp93 rather than C. sp90. There was no difference in mortality of domatia, with one death on C. sp90- and one on C. sp93-inhabited palms.

\section{Ant abundance}

Colonies of Camponotus sp90 inhabited 39\% of Korthalsia furtodoana palms sampled, whilst C. sp93 inhabited $27 \%$, and opportunistic Crematogaster spp. inhabited $9 \%$

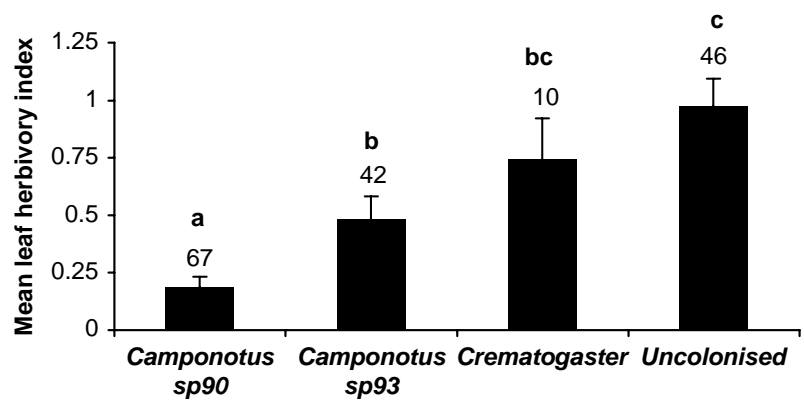

Figure 4. Leaf herbivory. The amount of mature leaf herbivory differed significantly between species (GLM: $F_{3,161}=20.8$, p < 0.001). Pairwise comparisions using a Tukey HSD post-hoc test revealed that plants inhabited by Camponotus sp90 suffered significantly less herbivory than those inhabited by $C . s p 93(\mathrm{p}=$ $0.011)$ or by Crematogaster $(\mathrm{p}=0.003)$, and that $C . s p 90$ - and C. $s p 93$-inhabited plants experienced significantly less herbivory than uncolonised saplings (both $\mathrm{p}<0.001$ ). The amount of leaf eaten was calculated using an index of herbivory. Letters denote significant differences at $\mathrm{p}<0.01$, sample sizes are given, and bars represent $\pm 1 \mathrm{SE}$. 


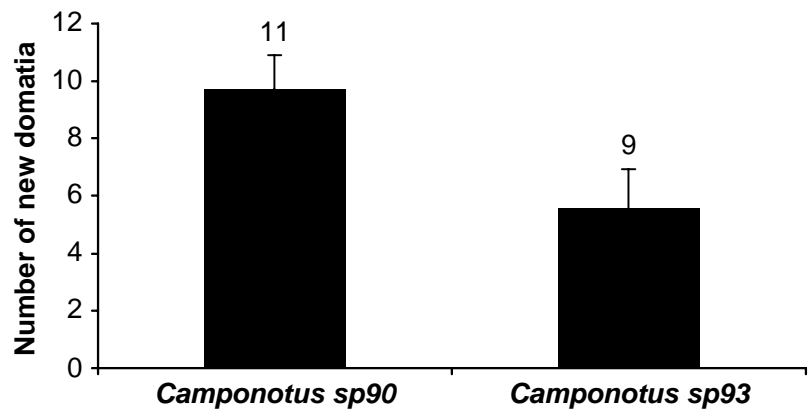

Figure 5. Plant growth. Plants inhabited by Camponotus sp 90 grew significantly more new domatia after nine months than did those inhabited by $C$. $s p 93$ (GLM: $\mathrm{F}_{1,18}=5.4, \mathrm{p}=0.032$ ). Sample sizes are given and bars represent $\pm 1 \mathrm{SE}$.

$\left(\mathrm{n}_{\text {total }}=188\right.$ plants $)$. The remaining $25 \%$ of plants were not yet colonised or were partially inhabited by a variety of other opportunistic 'tramp' ant species.

\section{Discussion}

This study provides strong evidence that the ant-palm Korthalsia furtadoana, which develops a new domatium before the attached new leaf (Fig. 1a-b), lacks a retaliatory sanction tying the growth and survival of housing to the protection of new leaves by ants. A host sanction that reduced the number of domatia would have the potential to impose a direct cost on non-protecting ants in this system, because reproductive output of ants is positively related to plant size. However, we found that experimental new leaf damage did not reduce the growth or survival of the attached domatia compared to undamaged controls, and thus there was no host sanction.

We then tested the theoretical expectation that systems that lack a host sanction will be commonly inhabited by cheaters. In the case of myrmecophytes that cannot tie housing to leaf growth, such cheaters are likely to be in the form of poorly-protecting ant species, which reside in the domatia but rarely patrol the leaves. Focusing on the obligate Camponotus and facultative Crematogaster hostants, we showed that only Camponotus sp90 symbionts vigorously patrolled leaves, whereas C. sp93 symbionts rarely (Fig. 2, 3) and Crematogaster never (Fig. 2) protected. Non-protection by $C$. sp93 resulted in a significant reduction in plant growth compared to plants inhabited by $C . s p 90$ (Fig. 5), confirming that housing non-protecting ants is costly to the host-plant. The observed reduction in plant growth was presumably due to greater herbivory on plants inhabited by non-protecting ants (Fig. 4).

A reduction in plant growth due to herbivory (Fig. 4, 5) clearly represents a cost to ants that are limited by plant size (Fonseca 1993, Edwards et al. 2006). We do not, however, consider such a growth reduction to be a sanction. Firstly, a reduction in plant growth due to general herbivory is not an evolved trait to punish cheaters, and occurs commonly in both ant-plants and non-myrmecophytes. Secondly, while cheating ants do pay a cost of reduced plant growth, this cost must be weighted against the price of investing in protection of the entire plant, which would naturally be very high. Indeed, even in the ant-Cordia nodosa system, ants vigorously protect new shoots to avoid a sanction, but invest far less in patrolling of mature shoots, resulting in herbivory and presumably an associated cost of reduced plant growth (Edwards et al. 2006). We thus restrict our definition of a host sanction to mechanisms that impose direct costs at the site of cheating, and note that in such cases, the payment for avoiding the sanction is likely to be low (e.g. protecting a new shoot vs an entire plant), while the costs of incurring the sanction will be comparatively high (Edwards et al. 2006).

These results lead us to conclude that the relationship between Camponotus sp90 and Korthalsia furtadoana is mutualistic, and that Crematogaster spp. are parasites of this system. The fact that C. sp93 provides some limited benefits to the host, in the form of reduced leaf herbivory compared to uncolonised plants (Fig. 4), means that hosting C. sp93 is better than hosting no ants (or tramp ants). However, despite this, C. sp93 does not appear to provide any invested benefit, with extremely limited patrolling that is not significantly different from zero (Crematogaster, Fig. 2). Furthermore, achieved plant growth is higher if the plant is inhabited by C. $s p 90$, and therefore the plant suffers an opportunity cost of hosting C. sp93 (Ferrière et al. 2007, Clement et al. 2008). We thus also class $C . s p 93$ a parasite of the $C \cdot s p 90-K$. furtodoana mutualism, but do note that there appear to be some byproduct benefits of hosting this species, possibly resulting from foraging. Interestingly, these results are the first empirical demonstration of mutualism and of parasitism in an ant-palm symbiosis, with previous such studies focusing on ant-tree systems (Janzen 1975, Gaume and McKey 1999, Raine et al. 2004, Tillberg 2004, Gaume et al. 2005, Palmer and Brody 2007). They strongly suggest therefore that ant-Korthalsia palm interactions should be considered as myrmecophytic systems.

Our results show that protecting C. sp90 ants only inhabited half of the colonised plants, with the remaining half being inhabited by obligate parasitic C. sp93 or by facultative parasitic Crematogaster ants. Additionally, 'uncolonised' plants can be (partially) inhabited by a variety of rare facultative, tramp ants, and we are uncertain as to whether these parasitic species can prevent the colonisation of saplings by winged-alates of $C . s p 90$. This, to our knowledge, provides the first correlative evidence that the lack of a host sanction permits abundant cheating. These results therefore complement the only other demonstration of host sanctioning in ant-plants, in which a host sanction tying leaf growth to domatia provision in the Cordia nodosa ant-tree correlates with intensive protection by over $95 \%$ of ant-symbionts (Yu et al. 2001, 2004).

Additional support for the concept that failure to sanction cheaters promotes non-protection is provided by the ant-plant Barteria nigritana, whose most common symbiont fails to remove herbivores (Djiéto-Lordon et al. 2004). The branches of $B$. nigritana produce domatia only along the basal half of their length, and therefore, it is unlikely that the development of leaves at branch tips is tied to the growth of each domatium (Edwards et al. 2006). In contrast, host sanctioning can be inferred in several other ant-plant systems, where development of the domatium is physically tied to the growth of a specific leaf or set 
(Edwards et al. 2006), and in each of these systems non-protecting cheaters are rare $(\leq 25 \%$ of inhabitants, Gaume and McKey 1999, Raine et al. 2004, Tillberg 2004, Frederickson 2005) or absent (Izzo and Vasconcelos 2002). Similarly, host sanctions in legume-rhizobia (Kiers et al. 2003, Kiers and van der Heijden 2006) and fig-fig wasp (Pellmyr and Huth 1994) interactions are important mechanisms promoting the maintenance of cooperation. To date, however, no study has experimentally identified a host in these or other systems that lacks the ability to impose a retaliatory sanction, and therefore the potential effects of a failure to punish on the abundance of cheaters.

\section{How far can an interaction evolve towards obligate mutualism without sanctioning?}

Observation suggests that patrolling by Camponotus sp90 might be not be an adaptation to a palm-ant lifestyle, in the sense that patrolling is a trait that arose because of a history of positive selection for patrolling per se (Edwards et al. 2007). Camponotus $s p 90$ vigorously attack insects on their host-palm (Edwards unpubl.), as well as the albeit defenceless termites (Fig. 3b), which are then removed to the domatia and presumably consumed. In contrast, the Allomerus ant-inhabitant of $C$. nodosa has a patroller caste that protects new leaves from herbivores, but that is unable to capture prey (Dejean et al. 2005, Edwards et al. 2007). Allomerus has presumably evolved the patroller caste in response to the host sanction tying leaf protection with domatia growth (see also Janzen 1966 for an example of aggressive mutualistic Pseudomyrmex workers killing and then discarding herbivores on their host Acacia trees). This suggests that whilst $C . s p 90$ has evolved as an obligate inhabitant of $K$. furtadoana, the provision of protection in this interaction remains, to some extent, a by-product benefit of foraging (see also 'by-product benefits' of C. sp93 discussed above). It seems likely therefore that the lack of a host sanction does not directly promote further adaptation to a mutualistic, palm-ant strategy, although such adaptations might occur as a result of partner fidelity feedbacks that accrue from inhabiting a larger plant (Fig. 5; Fonseca 1993, Edwards et al. 2006).

Our results therefore suggest the intriguing possibility that the lack of a host sanction allows both cooperating and cheating symbionts to increase their 'power' in the interaction with their host (Bergström et al. 2003, Frank 2003). We suggest that searching for other similar examples could greatly improve our understanding of the role of host retaliation in the evolution and maintenance of mutualism in a variety of systems, and might shed new light on why some systems are apparently frequently invaded by parasites.

Acknowledgements - We thank Glen Reynolds and the Royal Society's southeast Asia Rainforest Research Programme for logistical support, Seike Yamane for identification of Camponotus ants, and Douglas Yu and Tom Wenseleers for comments that greatly improved the manuscript. We also thank Yayasan Sabah (Forestry Division), Danum Valley Management Committee, the State Secretary (Internal Affairs and Research Office), Sabah Chief Minister's Dept, and the Economic Planning Unit of the Prime Minister's Dept, Kuala Lumpur, for permission to conduct research in Sabah. David Edwards was supported by a Leverhume Trust research grant, Paul Woodcock by a Univ. of Leeds studentship, and Tom Fayle by a NERC and NHM CASE studentship.

\section{References}

Bergström, C. T. et al. 2003. Group report: interspecific mutualism. Puzzles and predications. - In: Hammerstein, P. (ed.), Genetic and cultural evolution of cooperation. MIT Press, pp. 241-256.

Boomsma, J. J. 1989. Sex-investment ratios in ants - has female bias been systematically overestimated. - Am. Nat. 133: 517-532.

Bull, J. J. and Rice, W. R. 1991. Distinguishing mechanisms for the evolution of cooperation. - J. Theor. Biol. 149: 63-74.

Clement, L. W. et al. 2008. Strategies of a parasite of the antAcacia mutualism. - Behav. Ecol. Sociobiol. 62: 953-962.

Davidson, D. W. and McKey, D. 1993. Ant plant symbioses - stalking the Chuyachaqui. - Trends Evol. Ecol. 8: 326-332.

Dejean, A. et al. 2005. Arboreal ants build traps to capture prey. - Nature 343: 973.

Djiéto-Lordon, C. et al. 2004. Symbiotic mutualism with a community of opportunistic ants: protection, competition, and ant occupancy of the myrmecophyte Barteria nigritana (Passifloraceae). - Acta Oecol. 26: 109-116.

Doebeli, M. and Knowlton, N. 1998. The evolution of interspecific mutualisms. - Proc. Natl Acad. Sci. USA 95: 8676-8680.

Dransfield, J. 1984. The rattans of Sabah, Sabah forest record No 13. - Sabah Forest Dept, Sabah.

Dransfield, J. and Patel, M. 2005. Rattans of Borneo: an interactive key. - R. Bot. Gard. Kew.

Edwards, D. P. and Yu, D. W. 2007. The roles of sensory traps in the origin, maintenance, and breakdown of mutualism. - Behav. Ecol. Sociobiol. 61: 1321-1327.

Edwards, D. P. et al. 2006. Selection for protection in an antplant mutualism: host sanctions, host modularity, and the principal-agent game. - Proc. R. Soc. Lond. B 273: 595-602.

Edwards, D. P. et al. 2007. Protection in an ant-plant mutualism: an adaptation or a sensory trap? - Anim. Behav. 74: 377-385.

Ferdy, J. B. et al. 2002. Evolution of mutualism between globeflowers and their pollinating flies. - J. Theor. Biol. 217: 219-234.

Ferrière, R. et al. 2007. Evolution and persistence of obligate mutualists and exploiters: competition for partners and evolutionary immunization. - Ecol. Lett. 10: 115-126.

Fonseca, C. R. 1993. Nesting space limits colony size of the plantant Pseudomyrmex concolor. - Oikos 67: 473-482.

Foster, K. R. and Wenseleers, T. 2006. A general model for the evolution of mutualisms. - J. Evol. Biol. 19: 1283-1293.

Frank, S. A. 2003. Perspective: repression of competition and the evolution of cooperation. - Evolution 57: 693-705.

Frederickson, M. E. 2005. Ant species confer different partner benefits on two neotropical myrmecophytes. - Oecologia 143: 387-395.

Gaume, L. and McKey, D. 1999. An ant-plant mutualism and its host-specific parasite: activity rhythms, young leaf patrolling, and effects on herbivores of two specialist plant-ants inhabiting the same myrmecophyte. - Oikos 84: 130-144.

Gaume, L. et al. 2005. The fitness consequences of bearing domatia and having the right ant partner: experiments with protective and non-protective ants in a semi-myrmecophyte. - Oecologia 145: 76-86.

Heil, M. and McKey, D. 2003. Protective ant-plant interactions as model systems in ecological and evolutionary research. - Annu. Rev. Ecol. Evol. Syst. 34: 425-453. 
Heil, M. et al. 2004. Spatiotemporal patterns in indirect defence of a southeast Asian ant-plant support the optimal defence hypothesis. - J. Trop. Ecol. 20: 573-580.

Hoeksema, J. D. and Kummel, M. 2003. Ecological persistence of the plant-mycorrhizal mutualism: a hypothesis from species coexistence theory. - Am. Nat. 162: S40-S50.

Holland, J. N. et al. 2004. Evolutionary stability of mutualism: interspecific population regulation as an evolutionarily stable strategy. - Proc. R. Soc. Lond. B 271: 1807-1814.

Izzo, T. J. and Vasconcelos, H. L. 2002. Cheating the cheater: domatia loss minimizes the effects of ant castration in an Amazonian ant-plant. - Oecologia 133: 200-205.

Janzen, D. H. 1966. Coevolution of mutualism between ants and acacias in Central America. - Evolution 20: 249-275.

Janzen, D. H. 1975. Pseudomyrmex nigropilosa - parasite of a mutualism. - Science 188: 936-937.

Johnstone, R. A. and Bshary, R. 2008. Mutualism, market effects and partner control. - J. Evol. Biol. 21: 879-888.

Kiers, E. T. and Van der Heijden, M. G. A. 2006. Mutualistic stability in the arbuscular mycorrhizal symbiosis: exploring hypotheses of evolutionary cooperation. - Ecology 87: 1627-1636.

Kiers, E. T. et al. 2003. Host sanctions and the legume-rhizobium mutualism. - Nature 425: 78-81.

Mattes, M. et al. 1998. The rattan palm Korthalsia robusta Bl. and its ant and aphid partners: studies of a myrmecophytic association in the Kinabalu park. - Sabah Parks Nat. J. 1: 47-60.

Palmer, T. M. and Brody, A. K. 2007. Mutualism as a reciprocal exploitation: African plant-ants defend foliar but not reproductive structures. - Ecology 88: 3004-3011.

Pellmyr, O. and Huth, C. J. 1994. Evolutionary stability of mutualism between yuccas and yucca moths. - Nature 372: 257-260.

Raine, N. E. et al. 2004. Guards and thieves: antagonistic interactions between two ant species coexisting on the same ant-plant. - Ecol. Entomol. 29: 345-352.
Rico-Gray, V. and Oliveira, P. S. 2007. The ecology and evolution of ant-plant interactions. - Univ. Chicago Press.

Sachs, J. L. et al. 2004. The evolution of cooperation. - Q. Rev. Biol. 79: 135-160.

Shapiro, J. M. and Addicott, J. F. 2003. Regulation of mothyucca mutualisms: mortality of eggs in oviposition-induced 'damage zones'. - Ecol. Lett. 6: 440-447.

Tillberg, C. V. 2004. Friend or foe? A behavioral and stable isotopic investigation of an ant-plant symbiosis. - Oecologia 140: $506-515$.

West, S. A. and Herre, E. A. 1994. The ecology of the new-world fig-parasitizing wasps Idarnes and implications for the evolution of the fig-pollinator mutualism. - Proc. R. Soc. Lond. B 258: 67-72.

West, S. A. et al. 2002a. Sanctions and mutualism stability: when should less beneficial mutualists be tolerated? - J. Evol. Biol. 15: 830-837.

West, S. A. et al. 2002b. Sanctions and mutualism stability: why do rhizobia fix nitrogen? - Proc. R. Soc. Lond. B 269: 685-694.

Walsh, R. D. P. and Newberry, D. M. 1999. The ecoclimatology of Danum, Sabah, in the context of the world's rainforest regions, with particular reference to dry periods and their impact. - Philos. Trans. R. Soc. B 354: 1869-1883.

Whitmore, T. C. 1984. Tropical rain forests of the Far East (2nd ed.). - Clarendon Press.

Yu, D. W. 2001. Parasites of mutualisms. - Biol. J. Linn. Soc. 72: 529-546.

Yu, D. W. et al. 2001. An empirical model of species coexistence in a spatially structured environment. - Ecology 82: 1761-1771.

Yu, D. W. et al. 2004. Experimental demonstration of species coexistence enabled by dispersal limitation. - J. Anim. Ecol. 73: 1102-1114. 